\title{
CIÊNCIANATURA
}

\section{Tendência, variação espacial da soja e caracterização sócio econômica de municipios produtores do Paraná, Brasil}

\author{
Soybean trend and yield variation in association with economic and social caracterization in \\ Paraná state, southern Brazil
}

\author{
Vinicius Carmello \\ Universidade Estadual Paulista - UNESP, Presidente Prudente, SP, Brasil \\ Programa de Pós-Graduação em Geografia
}

\section{Resumo}

O estado do Paraná é o segundo maior produtor de soja do Brasil, ficando atrás apenas do estado do Mato Grosso. O objetivo deste artigo é analisar a tendência e a variação espacial dos dados de produtividade de soja, assim como realizar uma caracterização social e econômico dos municípios produtores para obter indicadores regionais que desvelam diferentes padrões de produtividade de soja em uma região representativa do Paraná entre 1999 até 2010. Foram coletados dados de produção de soja de 132 municipios, os quais representam toda a vertente paranaense da bacia do rio Paranapanema. Aplicaram-se dois testes estatísticos para mediar à variação temporal e espacial dos totais municipais de produtividade. O primeiro refere-se ao teste de Mann-Kendall e o segundo ao teste de Ward. Os resultados foram espacializados, e também representados em gráficos do tipo boxplot. Os principais resultados mostraram marcada variação espacial, assim como variações anuais da produtividade entre os municípios representativos. As variações anuais e espaciais possuem relação com as características agrícolas coletadas do Censo Agropecuário de 2006.

Palavras Chave: Paraná. Sul do Brasil. Soja. variação espacial. Ibaiti. Ponta Grossa. Santo Inácio.

\section{Abstract}

The Paraná State in Southern Brazil is the second most soybean producer from Brazil; Paraná comes behind only the Mato Grosso state in Brazilian central area. This paper aims to analyze the soybean trend and spatial variation productivity data, as well as carry out a social and economic characterization of the municipalities producers and thus create regional indicators unfold different patterns of productivity of soybean in a representative region of Paraná in the years between 1999 to 2010. To finish this research was collected soybean data from 132 counties. These counties represent the southern slope of Paranapanema river basin. Was applied two statistic testes: MannKendall and the Ward. The results were represented in cartographic system and boxplots graphics and they showed the visible soybean yield crop and spatial variation between all counties. The crop and spatial variation have relation with agriculture characteristics analyzed by IBGE data.

Keywords: Paraná. Southern Brazil. Soybean. spatial variation. Ibaiti. Ponta Grossa. Santo Inácio. 


\section{Breve introdução e justificativa}

A produção de soja possui forte representatividade no estado do Paraná, o que contribui para definir o perfil agrícola do estado, voltado, sobretudo para a exportação de grãos - setor agrícola. Essa característica agrícola é mesclada por vezes a um perfil agrícola menos industrializado e mais familiar como também a um perfil industrial. Este estado hoje é o segundo maior produtor de grãos do Brasil, com tendências de se tornar o primeiro.

O teste de tendência aplicado aos dados de produtividade mostrou exatamente essa característica (Quadro 1 / Figura 3). Este resultado é um indicador importante do que vem acontecendo na agricultura na escala local, regional e consequentemente, nacional. As políticas públicas, a intervenção do Estado e o desenvolvimento técnico estimulam esse aumento anual de produtividade (Figura 1).

Figura 1 - Exemplo da trajetória dos valores de produção de soja no Brasil, 1970 - 2007

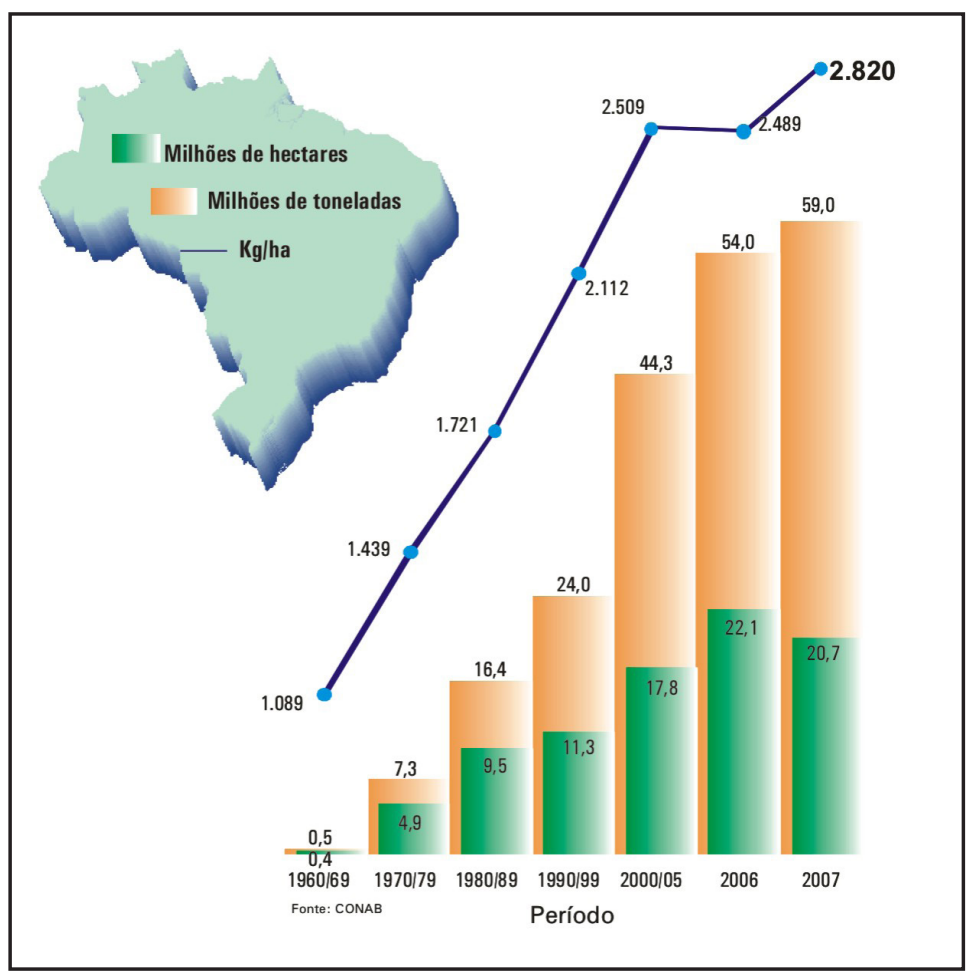

Fonte: AGEITEC

A elaboração deste artigo se justifica no que Martine e Garcia (1987) intitularam como “os impactos da modernização agrícola”, pois, sabe-se que nas últimas décadas, grande parte do espaço agrícola brasileiro foi afetada pelo abandono das formas tradicionais de produção em favor de outras, tecnologicamente avançadas (MARTINE; BESKOW, 1987, p. 19), entretanto, esse processo não se deu de forma homogênea e mesmo nas regiões onde não ocorreram alterações significativas na base tecnológica, à política de modernização teve fortes impactos sociais, via fortalecimento e penetração do complexo agroindustrial e/ou via majoração do preço da terra (MARTINE; BESKOW, 1987, p. 19).

Justifica-se também pelo fato da presença da soja no território brasileiro ter completado 131 anos em 2013 e, vem se apresentando vital para o cenário nacional e internacional, principalmente ao considerar os fatores econômicos relacionados à comercialização desse produto, à geração de empregos por trás de toda a logística que se faz necessária e; a segurança e integridade dos complexos agroalimentares, cuja soja possui representatividade ao considerá-la componente de uma cadeia produtividade. A cadeia produtiva da soja envolve as atividades de produção agrícola propriamente dita (lavoura, pecuária, extração de óleo vegetal) e aquelas relacionadas ao fornecimento de insumos nas ligações a montante (TAVARES, 2004).

Apesar destas características, a Funbio (2010) mostra que há questões contraditórias quando se considera a soja como produto considerado "carro chefe" das exportações do Brasil, principalmente ao considerar a concentração da terra, a produção com intensa mecanização visando à exportação, especialmente do grão sem beneficiamento, o impacto do plantio da soja na produção de alimentos locais e a precarização do trabalho, análoga ao trabalho escravo, principalmente, para a abertura de novas áreas para o plantio do grão.

É importante destacar que atualmente, o Brasil é o segundo maior produtor de soja no mundo e que produção de soja no Brasil aumentou em mais de 30 milhões de toneladas no intervalo de 2000 a 2010, com flutuações no decorrer da série histórica. 
O objetivo deste artigo é analisar a tendência e a variação espacial dos dados de produtividade de soja, assim como realizar uma caracterização social e econômica de municípios produtores localizados na vertente paranaense da bacia do rio Paranapanema. O período temporal determinado para aplicar os testes estatísticos foi entre as safras de 1999 até 2010.

A seguir são descritos os procedimentos metodológicos e posteriormente os resultados e a conclusão somada à discussão.

\section{2 - Procedimentos metodológicos}

Os dados de produção de soja, que posteriormente foram realizados os cálculos de produtividade, foram obtidos junto à SEAB - Secretaria da Agricultura e do Abastecimento do Paraná.

Foram realizados cálculos de desvio anual para os resultados gerados, integrando todos os 132 municípios, somando-se a produtividade e chegando a um valor total referente a toda área correspondente à vertente sul da bacia do rio Paranapanema. Optou-se pelo teste de Mann-Kendall para analisar a tendência na série história. Este teste é um é um procedimento baseado em posições e é amplamente utilizado na hidrologia e climatologia (BURN, 2008 apud TIAN, 2012). Para Zhang et al., (2009) este tipo de teste considera apenas os valores relativos de toda a série $\left(X=\left\{x_{1}, x_{2}, \cdots, \chi_{n}\right\}\right)$ para ser analisado. Este teste é dado pela seguinte equação:

$$
S=\sum_{i=1}^{n-1} \sum_{j=i}^{n} \operatorname{Sgn}\left(x_{j}-x_{i}\right)
$$

(1) - Equação que representa o teste de Mann-Kendall

Onde: $\chi_{i}$ e $\chi_{j}$ são a sequência dos dados e n é o conjunto de dados do comprimento do registro e distribuições espaciais e temporais.

Quanto ao agrupamento, optou-se pela técnica de Ward e pela representação em gráficos do tipo Boxplot (Fig. 2). Estes, segundo Silveira et al (2013), é um tipo de gráfico que pode ser interpretado da seguinte forma: primeiro quartil (Q1), valor que representa as $25 \%$ menores observações da amostra ordenada; o segundo quartil ou mediana (Q2), que divide o conjunto de dados em duas partes, de maneira que seu valor contemple 50\% das menores observações da amostra ordenada e; o terceiro quartil (Q3), o qual apresenta o valor até que se observa $75 \%$ da amostra ordenada.

Figura 2 - Esquema de um gráfico Boxplot

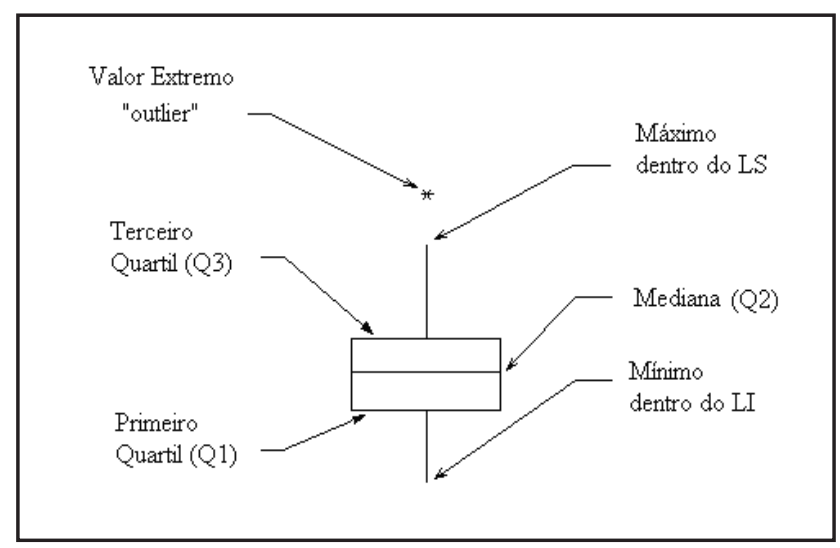

Org.: Silvestre, 2012 - publicado em Silvestre et al., 2013

Silveira et al (2013) descreve que o gráfico Boxplot é constituído de um retângulo e duas linhas, uma acima e outra abaixo do mesmo. A linha desenhada no centro do retângulo representa o valor da mediana (Q2), a linha inferior do retângulo o primeiro quartil (Q1) e, a linha no topo, o terceiro quartil (Q3). A partir do terceiro quartil é acrescentada uma linha que se estende até o maior valor observado para a variável, desde que esse não exceda o limite superior: LS=Q3+1,5(Q3-Q1). Abaixo do primeiro quartil, é representada outra linha que se estende até o menor valor observado da variável, desde que esse não exceda o limite inferior: $\mathrm{LI}=\mathrm{Q} 1-1,5(\mathrm{Q} 3-\mathrm{Q} 1)$. Os asteriscos representam as observações da amostra considerada como valores extremos, também chamados "outliers", os quais excedem os limites inferior ou superior.

Optou-se por determinar grupos homogêneos, segundo os níveis de produtividade da cultura. O objetivo foi identificar os municípios que apresentem diferentes níveis de produtividade e se os mesmos exibem proximidades, o que indicaria um processo de regionalização. Melo, Fontana e Berlato (2004) realizaram este procedimento para analisar a soja na região no noroeste do estado do Rio Grande do Sul, região que é responsável por $90 \%$ da produção de soja do estado. 
Estes procedimentos foram realizados utilizando o método Ward (aglomeração hierárquica) e pela medida da distância euclidiana entre os pares de objetos (municípios), conforme Wilks (1995). Esta aglomeração contribui para um conhecimento detalhado da produção de soja entre os municípios da vertente sul do Paranapanema e consequentemente para definir as diferenças e determinar os padrões regionais. $\mathrm{Na}$ análise descritiva dos grupos formados a partir do método de Ward, conforme, destacam-se: produtividade média, máxima e mínima, além do número de municípios que se enquadram em cada um destes grupos (Grupo P1, Grupo P2 e Grupo P3). Por último, os resultados foram representados num sistema de informações geográficas no programa ArcGIS, onde foi possível espacializar os resultados representativos.

Quanto à coleta dos dados para alicerçar e gerar discussão acerca das características de cada grupo de municípios, foram escolhidos três municípios representativos:

Grupo P1 - Ponta Grossa - alta produtividade;

Grupo P2- Ibaiti - média produtividade;

Grupo P3 - Santo Inácio - baixa produtividade.

Em seguida, buscaram-se no site do IBGE - Instituto Brasileiro de Geografia e Estatística e mais especificamente no Censo Agropecuário de 2006, informações relevantes que pudessem contribuir para levantar o perfil dos três municípios, tais como:

Total de área destinado à agricultura;

Total de área destinado à produção de soja;

Produção em toneladas de cana-de-açúcar;

Produção em toneladas de mandioca;

Número de estabelecimentos com tratores;

Número de estabelecimentos que realizaram benfeitoria em suas propriedades

\section{3 - RESULTADOS}

Na região de estudo, houve quedas da produtividade de soja nos anos agrícolas de 1999/00, 2004/05, 2005/06 e 2008/09 e, de uma forma contrária, aumentos dos valores finais de safra em 2000/01, 2002/03, 2006/07, 2007/08 e 2009/10, sendo este último, o que apresentou melhores ganhos (Fig. 3).

Figura 3 - Desvio de produtividade agrícola - 132 municípios

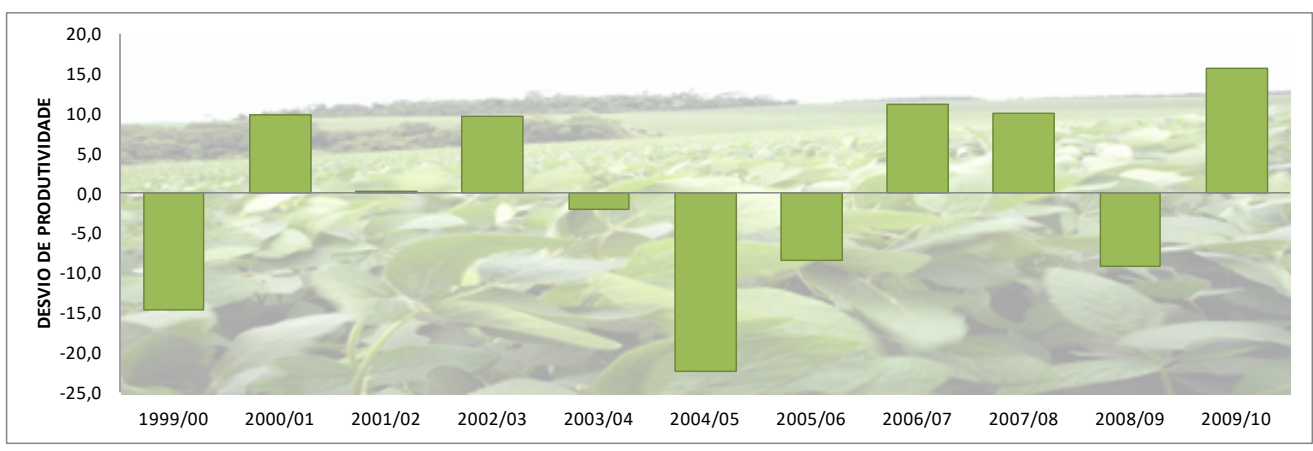

Fonte de dados: SEAB (2011). Org.: Carmello (2011). Fonte: Carmello (2013)

Dos 132 municípios estudados, 15 apresentaram tendência de aumento de produtividade entre 1999-2010. A área homogênea, na porção oeste, é formada pelos municípios de Carlópolis, Congonhinhas, Conselheiro Mairink, Ivaí, Joaquim Távora, Leópolis, Pinhalão, Ribeirão do Pinhal, Salto do Itararé, Santa Amélia, Santo Antonio do Paraíso, São Jerônimo da Serra, Sapopema, Siqueira Campos e Wenceslau Braz (Fig. 4).

A tendência negativa apresentada pelo município de Santo Inácio, na região de Paranavaí, porção noroeste do Paraná possui relação tanto com o perfil agrícola, quanto às questões físicas e sociais. Se for analisado, por exemplo, o contexto físico dessa região, perceberse-á que o perfil pedológico se diferencia das demais partes do Estado, há a predominância arenítica do solo. Já, se analisado as questões sociais, outra característica é apontada por Ramos, Boava e Donato (2011).

Estas autoras mostraram que existe forte influência dos movimentos de assentado na região, influenciando o perfil agrícola da região. Existem de 1 a 10 assentamentos em Terra Rica, São João do Caiuã, Paranacity e Nova Londrina, sendo que o município com maior número de assentamentos é Querência do Norte. 
Quadro 1 - Representação dos resultados do teste de Mann-Kendall

\begin{tabular}{|c|c|c|c|}
\hline Testes Estatísticos & $\begin{array}{c}\text { Rupturas/Tendência } \\
\text { Positiva (+) }\end{array}$ & $\begin{array}{c}\text { Rupturas/Tendência } \\
\text { Négativa (-) }\end{array}$ & $\begin{array}{c}\text { Sem tendência/ } \\
\text { rupturas }\end{array}$ \\
\hline Teste de Mann-Kendall anual & 15 & 1 & 116 \\
\hline
\end{tabular}

Org.: Carmello, 2013; Fonte: Carmello (2013)

Figura 4 - Resultado de Mann-Kendall para os dados de produtividade Org.: Carmello (2012)

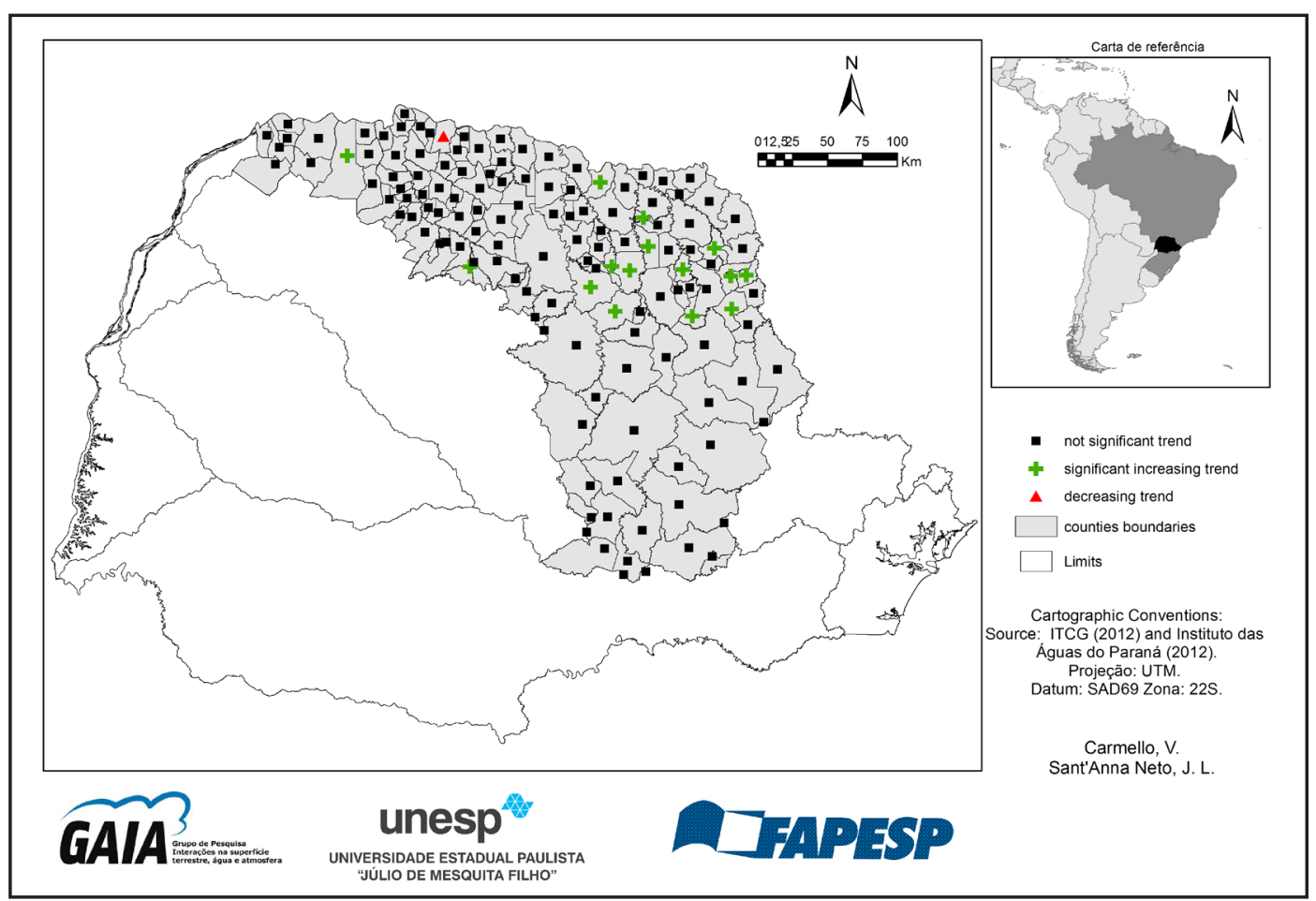

Fonte: Carmello (2013); Carmello e Sant'Anna Neto (2016)

\section{1 - Estatísticas descritiva, gráfica e variação espacial da produtividade de soja.}

Os três grupos de produtividade da soja estão representados no gráfico da Figura 5. Os municípios do primeiro grupo podem ser observados no Box, em que a produtividade média anual mostra variação entre 2 ton/ha até 3 ton/ha. Já os do segundo grupo (P2) mostram maior variação, porém, a maioria dos municípios, possuiu uma produtividade média anual acima de 2 ton/ha.

Figura 5 - Produtividade média anual relativa ao período 1999/00 a 2009/10, considerando os grupos formados pelo método de Ward

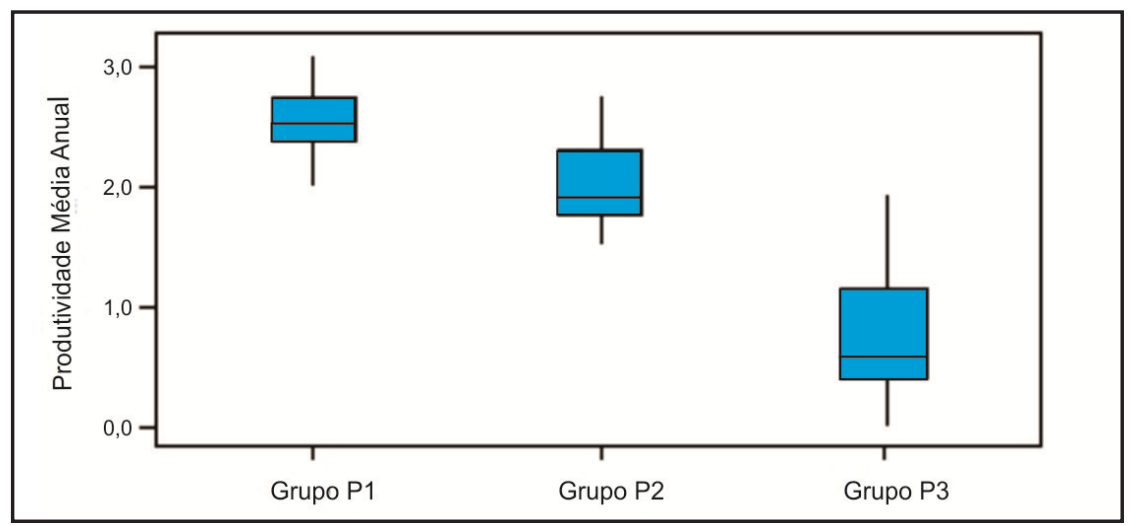

Org.: Silvestre e Carmello (2011). Fonte: Carmello (2013); Carmello, Silveira e Sant' Anna Neto (2014) 
Já no terceiro grupo (P3), a variação é bastante ampla, sendo que os municípios desse grupo demonstram uma produtividade média anual abaixo de 1 ton/ha. Percebe-se a quantidade de municípios que foram classificados no grupo P1, o de maior produtividade, no total de 106 municípios; no grupo P2, de produtividade média, 14 municípios e; no grupo P3, com menor produtividade, 12 municípios (Tabela 1).

Tabela 1 - Estatística descritiva dos grupos formados pela análise de cluster (método de Ward)

\begin{tabular}{l|c|c|c|c}
\hline Grupo & No de Municípios & Média & Mínima & Máxima \\
\hline GRUPO P1 & 106 & 2.549 & 2.011 & 3.128 \\
\hline GRUPO P2 & 14 & 1.943 & 1.520 & 2.796 \\
\hline GRUPO P3 & 12 & 0.578 & 0.000 & 1.953 \\
\hline
\end{tabular}

Org.: Carmello, 2011

Encontram-se no grupo P1, os municípios que apresentaram produtividade média entre 2.011 (kg/ha) e 3.128 (kg/ha). No Grupo P2 verificam-se os municípios cuja produtividade esteve entre 1.520 (Kg/ha) e 2.796 (Kg/ha). Já o Grupo P3 constituise daqueles municípios que apresentaram média de produtividade entre 0 e $1.953(\mathrm{Kg} / \mathrm{ha})$. A produtividade é considerada alta nas proximidades dos municípios de Ponta Grossa, Castro e Telêmaco Borba, assim como nas áreas próximas às regiões de Maringá e Londrina, num total de 106 municípios (Fig. 6).

Figura 6 - Distribuição da produtividade média anual relativa ao período 1999/00 a 2009/10

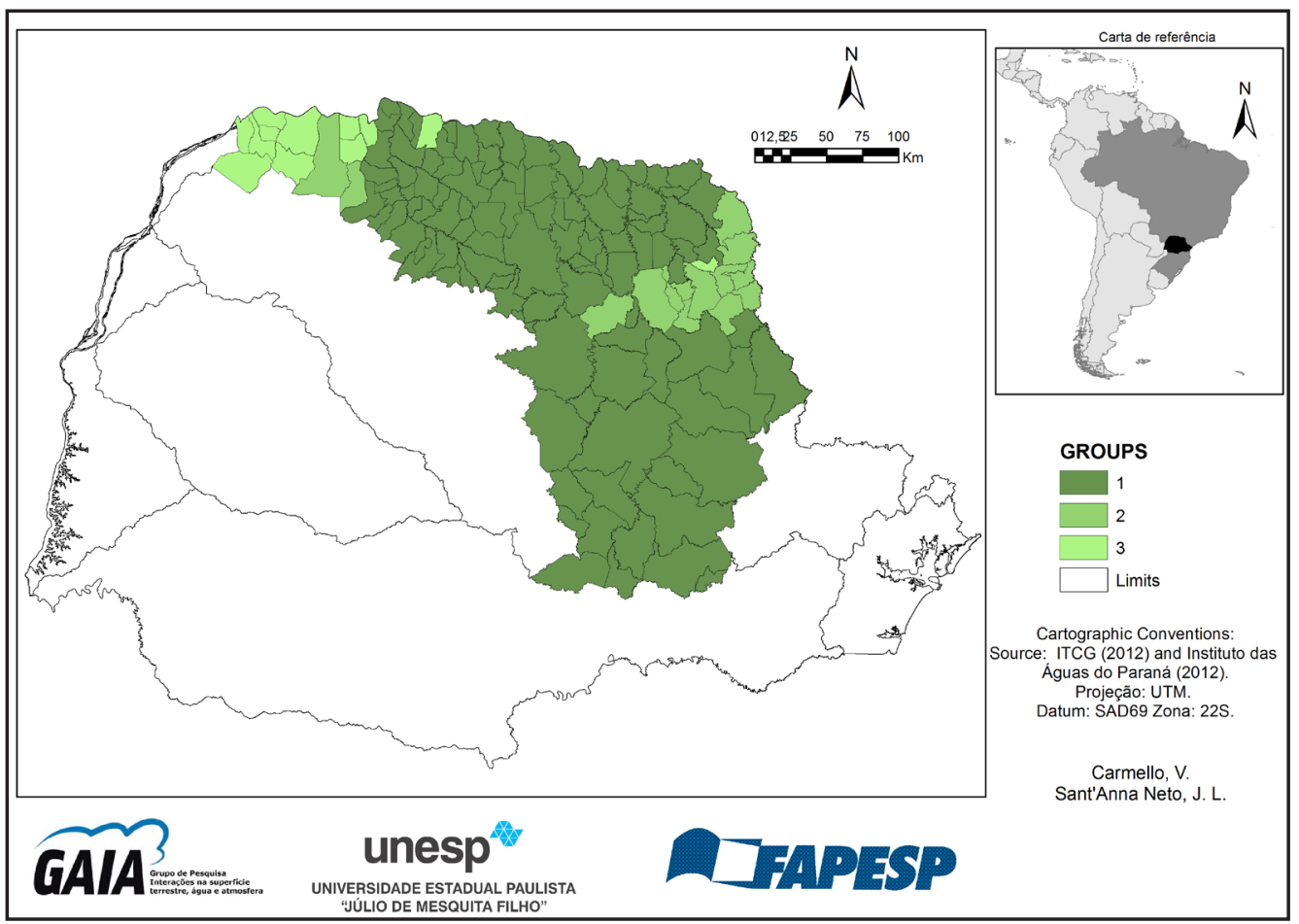

Org.: Carmello (2012); Fonte: Carmello, Silveira e Sant'Anna Neto (2014); Carmello (2013).

Os municípios do Grupo P2 estão na porção leste (maior concentração) e a noroeste, num total de 14 municípios. Neste grupo encontram-se municípios como Paranavaí, Jacarezinho, Sapopema, Ribeirão Claro, Ibaiti, Wenceslau Braz, Santana do Itararé, etc. Os municípios do Grupo P3 agruparam-se na porção próxima ao município de Paranavaí, contabilizando um total de 12 municípios, representados por cidades, como Loanda, Nova Londrina, Diamante do Norte, Guairaça, Quatiguá, Santo Inácio, entre outros.

Os resultados que mostraram a variação interanual da produtividade agrícola entre as safras, tanto aqueles relacionados ao desvio de produtividade agrícola da cultura da soja, quanto os testes de tendência mostraram um descompasso na série histórica. Porém, verificou-se que há um padrão espacial entre os municípios (Grupos P1, P2 e P3).

Foi escolhido um município representativo de cada grupo de produtividade para levantar os dados do Censo agropecuário de 2006, disponibilizado pelo IBGE. Optou-se por representar e analisar a variabilidade da produtividade de soja entre os três municípios. Esta representação mostra marcada variabilidade anual entre os três munícipios (Fig. 7 e Tabela 2), exceto pela safra de 2006/07. Os valores expressivos e consequentemente a menor variância ocorreu no ano de 2006/07 (maior valor: 3,200 $\mathrm{kg} / \mathrm{ha}$ e menor valor: $2,990 \mathrm{~kg} / \mathrm{ha}$ ) e o contrário ocorreu em 2004/05. 
O maior nível de variância entre os municípios ocorreu em 2009/10 (resultado da ausência de valores em Santo Inácio em 1999/10) e em seguida em 2003/04. Neste último, o maior registro de produtividade foi de 3,000 kg/ha (Ponta Grossa) e o menor registro foi de $1,226 \mathrm{~kg} / \mathrm{ha}$ (Santo Inácio).

Figura 7 - Produtividade de soja entre os municípios de Ibaiti, Ponta Grossa e Santo Inácio

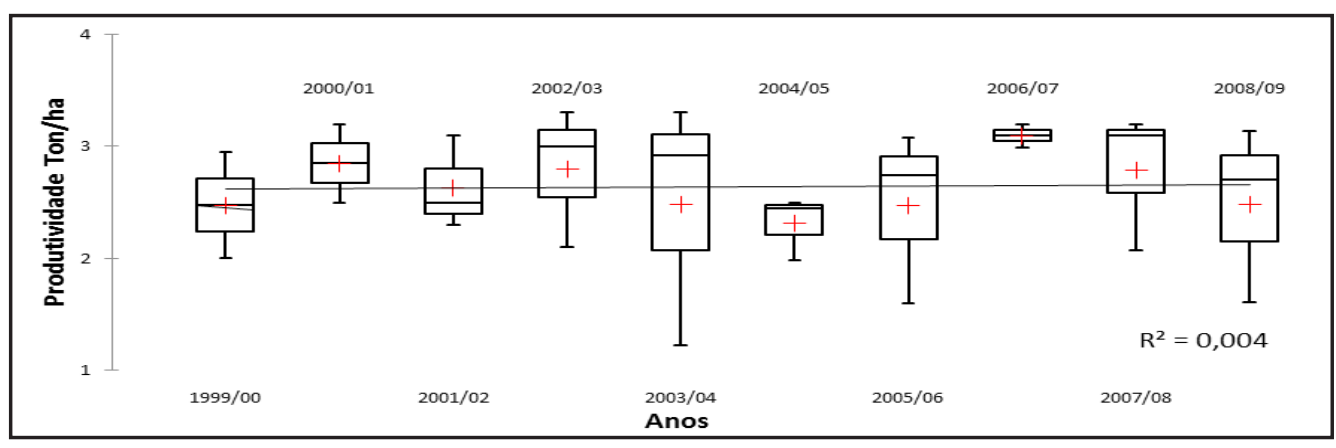

Org.: Carmello (2015)

Tabela 2 - Características da produtividade de soja nos três municípios

\begin{tabular}{l|c|c|c|c|c|c|c|c|c|c|c}
\hline Estatística & $\mathbf{1 9 9 9 / 0 0}$ & $\mathbf{2 0 0 0 / 0 1}$ & $\mathbf{2 0 0 1 / 0 2}$ & $\mathbf{2 0 0 2} / \mathbf{0 3}$ & $\mathbf{2 0 0 3 / 0 4}$ & $\mathbf{2 0 0 4} / \mathbf{0 5}$ & $\mathbf{2 0 0 5} / \mathbf{0 6}$ & $\mathbf{2 0 0 6 / 0 7}$ & $\mathbf{2 0 0 7 / 0 8}$ & $\mathbf{2 0 0 8 / 0 9}$ & $\mathbf{2 0 0 9 / 1 0}$ \\
\hline Mínimo & 2,000 & 2,500 & 2,300 & 2,100 & 1,226 & 1,980 & 1,600 & 2,990 & 2,070 & 1,610 & 0,000 \\
\hline Máximo & 2,950 & 3,200 & 3,100 & 3,300 & 3,300 & 2,500 & 3,079 & 3,200 & 3,200 & 3,138 & 3,200 \\
\hline $1^{\circ}$ Quartil & 2,238 & 2,675 & 2,400 & 2,550 & 2,073 & 2,215 & 2,174 & 3,045 & 2,585 & 2,155 & 1,488 \\
\hline Mediana & 2,475 & 2,850 & 2,500 & 3,000 & 2,921 & 2,450 & 2,747 & 3,100 & 3,100 & 2,700 & 2,975 \\
\hline $3^{\circ}$ Quartil & 2,713 & 3,025 & 2,800 & 3,150 & 3,111 & 2,475 & 2,913 & 3,150 & 3,150 & 2,919 & 3,088 \\
\hline Média & 2,475 & 2,850 & 2,633 & 2,800 & 2,482 & 2,310 & 2,475 & 3,097 & 2,790 & 2,483 & 2,058 \\
\hline Variância & 0,451 & 0,245 & 0,173 & 0,390 & $\mathbf{1 , 2 2 0}$ & 0,082 & 0,602 & $\mathbf{0 , 0 1 1}$ & 0,391 & 0,619 & 3,190 \\
\hline
\end{tabular}

Org. Carmello (2015)

\section{2 - Análise dos dados do senso agropecuário de 2006 para os municípios representativos da região de estudo}

A Tabela 3 traz uma série de variáveis inerentes às atividades no campo, como a média de área plantada com soja, considerando os dez anos; a área total dos municípios; a área total destinada à agropecuária; a porcentagem de área destinada à cultura da soja; o resultado do agrupamento; a quantidade de estabelecimentos agropecuários por municípios; os tipos de uso e, etc.

O município de Ibaiti, apesar de apresentar uma área total destinada à agricultura inferior a 40 mil hectares, se comparado com Ponta Grossa, possui um número maior de estabelecimentos agropecuários. Isso leva a possíveis interpretações acerca da área total dos estabelecimentos agropecuários nos dois municípios, levando a crer que Ibaiti possui quantidade superior de propriedades de menor porte.

Tabela 3 - Principais características dos municípios representativos

\begin{tabular}{l|c|c|c}
\multicolumn{1}{c|}{ Município } & Ibaiti & Ponta Grossa & Santo Inácio \\
\hline Grupo de produtividade & 2 & 1 & 3 \\
\hline Número de estabelecimentos agropecuários & 1566 & 1522 & 288 \\
\hline Área total destinada à agricultura & 62.697 ha & 104.586 ha & 27.523 ha \\
\hline Área total do município & 90.023 ha & 202.570 ha & 30.849 ha \\
\hline Média de área total plantada com soja & 3817 ha & 55929 ha & 1422 ha \\
\hline $\begin{array}{l}\text { Relação da média da área destinada para } \\
\text { soja com a área dos estabelecimentos agro- } \\
\text { pecuários }\end{array}$ & $6 \%$ & $53 \%$ & $5 \%$ \\
\hline Demais usos: Matas, florestas e reservas & 12.883 ha & 38.296 ha & 1.294 ha \\
\hline
\end{tabular}


Apresentar propriedades rurais de menor porte pode refletir nas formas e também no tipo de cultura que estão sendo cultivadas. Moro (1995) mostra que depois do café, a cultura da soja e do milho sucederam a monocultura comercial da paisagem agrícola do Paraná e que esse tipo de cultura necessita de áreas de terra bem superiores àqueles das pequenas e médias propriedades. O autor acrescenta que a característica das propriedades que possuem tradição no cultiva da soja, reflete nos resultados, sobretudo àqueles oriundos da relação do total da área destinada à cultura da soja com a o total da área destinada à agricultura pelos municípios (Fig. 8).

Ibaiti e Santo Inácio apresentam uma relação pouco significativa entre essas duas variáveis, se comparado com Ponta Grossa. Em média, esses municípios destinam 6\% e 5\%, respectivamente, do total da área agrícola para a produção de soja, sendo que Ponta Grossa destinou em 2006, 53\%. Há um maior número de propriedades agrícolas de grande porte em Ponta Grossa e, consequentemente, uma tradição pelo cultivo de lavouras temporárias, como a soja e o milho, corroborando as afirmações de Moro (1995).

Figura 8 - Relação da área destinada à cultura da soja com a área total destinada aos estabelecimentos agropecuários por município em 2006

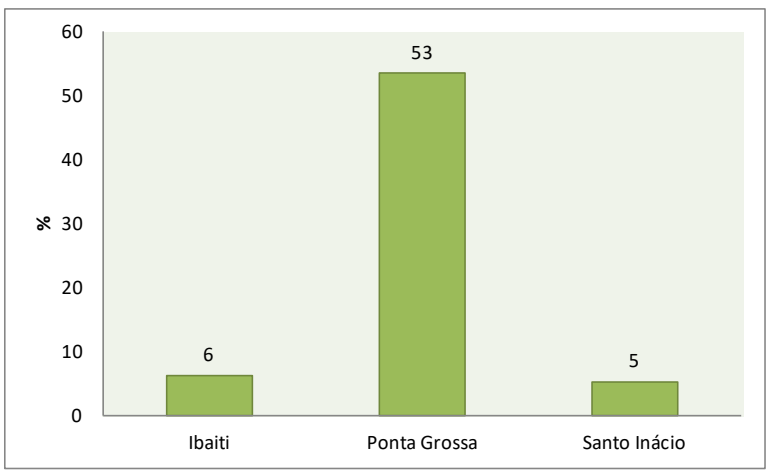

Fonte dos dados: Censo Agropecuário 2006. Org.: Carmello (2013)

Figura 9: Produção em toneladas de cana-de-açúcar(a). Produção em toneladas de mandioca (b)
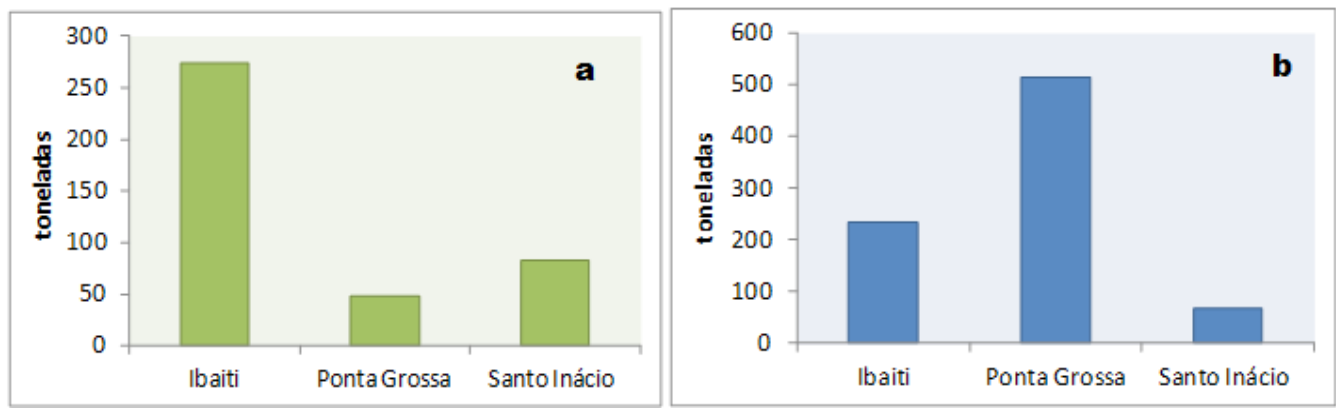

Fonte dos dados: Censo Agropecuário, 2006. Org.: Carmello, 2013

Ibaiti apresentou uma produção total de cana-de-açúcar superior a Ponta Grossa e Santo Inácio (Fig. 9a). Já em relação à produção de mandioca, nota-se que Ponta Grossa apresentou uma produção total consideravelmente superior em 2006, acima de 500 (t), seguido por Ibaiti, aproximadamente 200 (t) e Santo Inácio, com pouco mais de 60 (t) (Fig. 9b). Tanto a soja quanto a cana-de-açúcar são cultivos associados à monocultura, percebe-se que Ponta Grossa possui uma tradição maior quanto à soja.

Os dados de produção de mandioca indicam que no município de Ponta Grossa não são encontrados apenas produtos destinados à exportação ou relacionados à monocultura, como a soja e o trigo, por exemplo. Outro dado coletado no Censo agropecuário disponibilizado pelo IBGE é o da quantidade de estabelecimentos que possuem maquinário do tipo trator (Fig. 9a). Com esse tipo de variável é possível observar quais municípios possuem maior acesso a fatores que intensificam o manejo e as atividades agrícolas. Espera-se que a quantidade de tratores, por exemplo, acompanhe a quantidade de propriedades agrícolas. Entretanto, ao comparar Ibaiti e Ponta grossa percebem-se as diferenças.

Conforme a Tabela 3 Ibaiti possui 1566 propriedades agropecuárias e Ponta Grossa, 1522 e mesmo com um número superior de propriedades agrícolas, Ibaiti possui apenas $11 \%$ delas com tratores, sendo que $35 \%$ dos estabelecimentos agrícolas de Ponta Grossa possuem acesso a esse tipo de maquinário e, em Santo Inácio são 26\%.

Quando se incorpora ao processo de produção agrícola os insumos (máquinas) há um rápido incremento de produtividade, e consequentemente, uma destruição da economia natural, ou seja, a técnica passa a controlar a natureza (CAMPOS, 2011, p.168). Moreira (2007) considera que a enxada e o arado, por exemplo, fazem um todo em ambientes com o cultivo de cul- 
turas diversas, em regiões distintas do globo, sobretudo, as de cunho familiar: assim como o trator, que perante a agricultura moderna, faz um tudo em cultura especializadas, desde o começo da agricultura industrial até os dias atuais.

Dessa maneira, é inerente relacionar a maior quantidade de tratores, sendo este um dos indicadores para entender o tipo de manejo do local, com propriedades grandes que direcionam sua produção ao mercado externo, priorizando as monoculturas sazonais. Paulino (2011) mostrou que a pequena propriedade é tida como reduto da baixa produtividade e da incapacidade de produzir em escala compatível com as demandas do mercado, resultante do baixo investimento do Estado.

Ibaiti apresenta uma quantidade mais elevada de pequenas propriedades agrícolas, conforme mencionado anteriormente. Nesse município há um número elevado de propriedades em uma área reduzida destinada à agricultura (62.697 hectares), se comparado com Ponta Grossa. Ponta Grossa possui 104.586 hectares destinados à agricultura, porém com menor quantidade de propriedades agrícolas e com maiores investimentos em construções e benfeitorias, assim como quantidades de tratores.

As características agrícolas relacionadas ao município de Ponta Grossa, juntamente com o resultado do agrupamento onde grande parte dos municípios apresentou produtividade alta de soja (Grupo P1), somado aos resultados de tendência de aumento da produtividade em 15 municípios, podem ser reflexos do desenvolvimento técnico e dos investimentos do Estado em prol de articulações e interesses visando resultados que estejam relacionados aos complexos agroindustriais. Campos (2011) defende que este perfil da agricultura depende diretamente do desenvolvimento do setor industrial, de máquinas e equipamentos, com interesses do Estado que passou a representar interesses agrários, industriais e financeiros.

Figura 10 - número de estabelecimentos agropecuários com tratores (a). número de estabelecimentos agropecuários que realizaram construções e benfeitorias no ano de 2006(b)

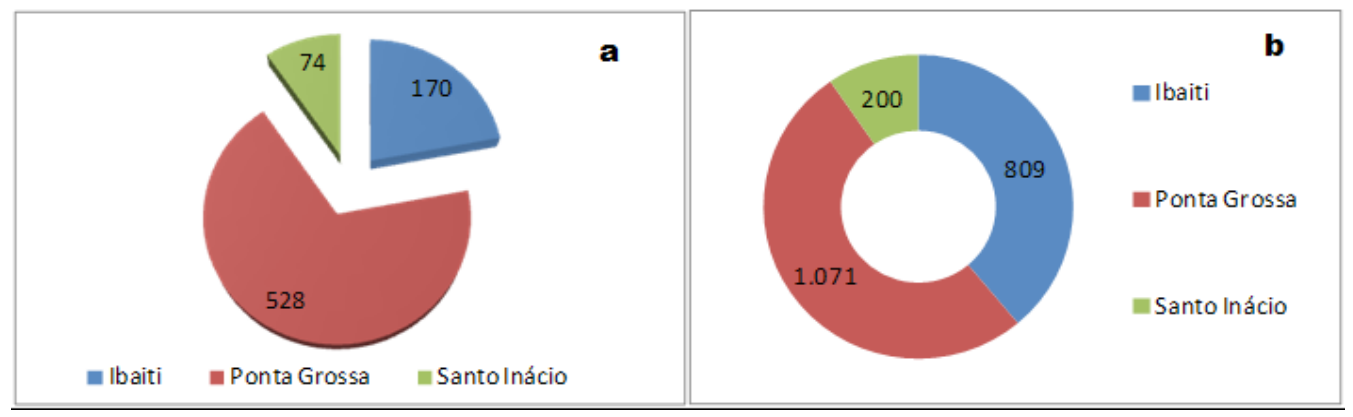

Fonte dos dados- Censo Agropecuário 2006. Org.: Carmello, 2013. Fonte: Carmello (2013); Carmello et al., (2014)

Outra variável apresentada mostra o número de estabelecimentos agropecuários que realizaram construções e benfeitorias1 em suas estruturas físicas (Fig. 10b). Das 1522 propriedades agrícolas em Ponta Grossa, cerca de 70\% realizaram algum tipo de benfeitoria ou construção, em Ibaiti, 52\%. Mesmo localizado no grupo P3 de produtividade agrícola, Santo Inácio mostra que $69 \%$ das propriedades localizadas em seus limites receberam algum tipo de benfeitoria.

Os investimentos no campo, por vezes, associam-se às formas desiguais de distribuição de renda, relacionadas a interesses políticos e econômicos. A modernização do campo é um processo "doloroso", justamente porque as relações de produção no meio rural privilegiam, sobremaneira, as frações do capital monopolista e em menor notoriedade, os pequenos e médios (MORO, 1995).

Tudo indica que Santo Inácio possui outra dinâmica quanto à agricultura, assim como os demais municípios do Grupo P3 de produtividade agrícola. Os municípios deste grupo, tomando base por Santo Inácio, mesmo com investimentos no campo, (69\% de propriedades que receberam algum tipo de interferência benéfica e com $26 \%$ da propriedade com tratores), não apresentam expressiva produtividade quanto à cultura da soja. O município de Santo Inácio foi o único que apresentou tendência de diminuição da produtividade de soja no período da década estudada, (ver mapa Fig. 5). No mesmo sentido, Santo Inácio não possui expressividade, por exemplo, com a produção de cana-de-açúcar, conforme questionado anteriormente.

Considerando as duas variáveis (tratores e construções/benfeitorias), conclui-se que Ibaiti, mesmo apresentando um número superior de propriedades agrícolas, porém com indicadores que mostram serem propriedades de pequeno e médio porte, registrou a menor relação tratando-se das duas variáveis mencionadas, sobretudo a de número de tratores. Quando se trata da análise dos dados que mostram a quantidade de pessoas ocupadas com atividades no campo nos três municípios (Fig. 11), é possível notar que a tendência segue o mesmo padrão das demais variáveis, com Ponta Grossa registrando o maior número, tratando-se do dado único e Santo Inácio com o menor índice, intermediado por Ibaiti.

A diferença entre Ponta Grossa e Ibaiti é de 1178 pessoas. Porém, se comparar proporcionalmente o número total da população de cada município com o total de indivíduos ocupados com atividade agrícolas (Fig. 12), verifica-se que $2 \%$ da população de Ponta Grossa, entre aqueles que residem no urbano e no rural, trabalham no campo, já em Ibaiti, essa porcentagem é de $14 \%$. Esta relação pode ser observada nos gráficos seguintes.

1 Os tipos de benfeitorias não são especificados pelo IBGE. 
Figura 11 - Pessoal ocupado em estabelecimentos agropecuários

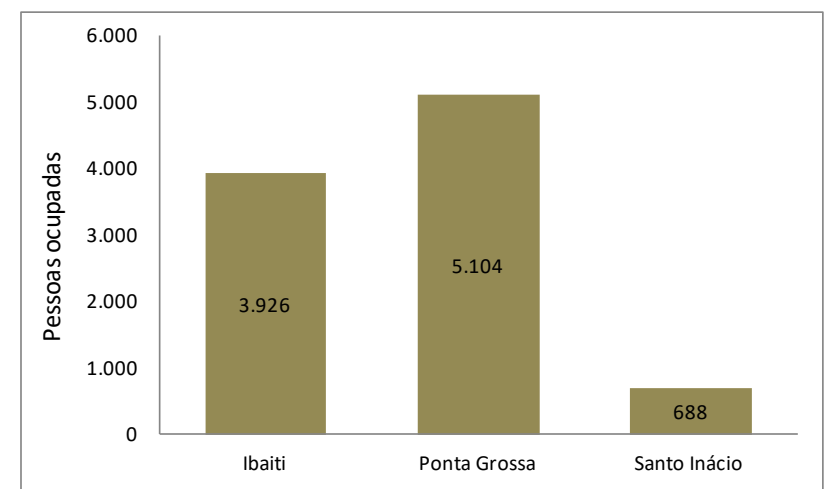

Fonte dos dados - Censo Agropecuário 2006. Org.: Carmello, 2013

Figura 12 - Relação entre o total da população residente por município e do pessoal ocupado em estabelecimentos agropecuários

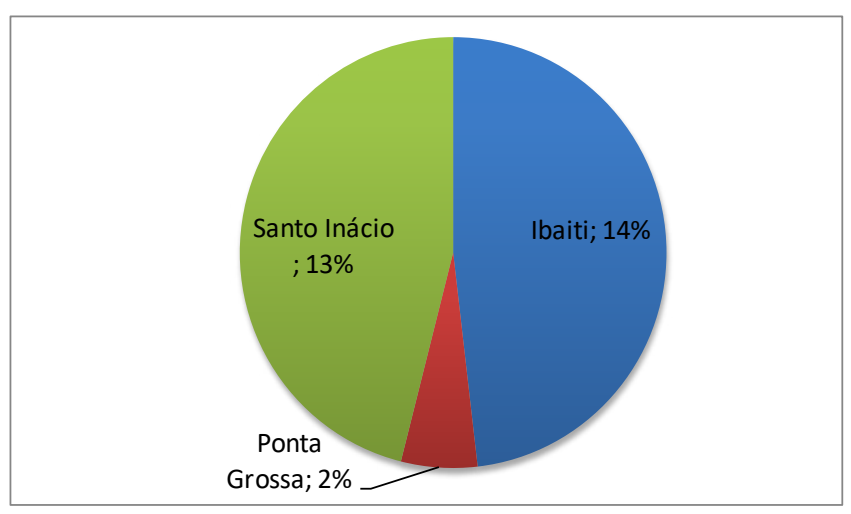

Fonte dos dados - Censo Agropecuário (2006) e do Censo populacional (2010). Org.: Carmello, 2013

O município de Ponta Grossa é o maior em relação à área territorial administrativa, assim como, à quantidade que destina para a agricultura, ao número de propriedades que possuem tratores (35\%), ao número de estabelecimentos que realizaram benfeitorias/construções (70\%). Porém, ele não se destaca quanto à quantidade de estabelecimentos agropecuários, indicando a grande quantidade de propriedades de grande extensão e da quantidade de pessoal ocupado com as atividades agrícolas. Esses indicadores remetem a uma agricultura mecanizada, de custo elevado e voltada à monocultura, mostrando, assim, a mecanização e, depois, a "tecnificação" do mundo rural contribui certamente para a queda da participação da população rural (SANTOS e SILVEIRA, 2001 apud CAMPOS, 2011).

Paulino (2011) concluiu que ao contrário do que se proclama, e se executa em termos de políticas territoriais para o campo, são exatamente os pequenos estabelecimentos os mais produtivos e os que mais geram empregos. É válido salientar que esta relação se dá considerando o tipo e a forma de conduzir as atividades no campo, assim como o tipo de cultura que é cultiva. Não se deve generalizar este mesmo perfil e atribuir estas mesmas características aos demais 105 municípios presentes no Grupo P1, pois cada um possui especificidades. Entretanto, conforme a metodologia adotada, ao elencar Ponta Grossa como município representativo e, considerando as variáveis elencadas para caracterizar seu perfil agrícola, percebe-se que para alcançar alta produtividade de soja é praticamente inerente possuir investimentos, mecanização e manejo (SORJ, 1980).

Ibaiti, se comparada à Ponta Grossa, destaca-se por apresentar maior quantidade de propriedades destinadas à agricultura, porém em uma área municipal reduzida. O município de Ibaiti possui a menor relação de tratores por propriedade (11\%), os menores investimentos em benfeitorias/construções e, a maior relação quando se trata da porcentagem de pessoas que trabalham ou se ocupam com atividades agrícolas (14\%).

Nota-se, também, que neste município o número total de produção de cana-de-açúcar é consideravelmente superior aos demais, mostrando um perfil agrícola diferente se comparado ao de Ponta Grossa. O município de Santo Inácio, representativo para o Grupo P1 de baixa produtividade de soja, apresentou, na maioria das vezes, os menores valores, considerando as principais variáveis relacionadas ao censo agropecuário. Isto pode ser justificado pela extensão territorial deste município, já que é o menor entre os três. Lembrando que este município é único que apresentou tendência de diminuição da produtividade. 


\section{4 - Conclusão e Discussão}

O objetivo do artigo foi analisar a tendência e a variação espacial dos dados de produtividade de soja, assim como realizar uma caracterização social e econômica de municípios produtores localizados na vertente paranaense da bacia do rio Paranapanema. Observaram-se três regiões homogêneas, com grupos de produtividade divididos por alta, média e baixa. Cada qual, com características agrícolas distintas, definidas a partir de variáveis obtidas junto ao censo agropecuário de 2006 . Estes dados mostraram alguns elementos favoráveis para explicar o agrupamento.

Por exemplo, os municípios se diferenciam com forte influência do total da área em que ocupam e, consequentemente, do total que destinam para a agricultura e para a soja. Pode-se asseverar que as regiões, onde estão localizados os municípios dos grupos P2 e P3 (média e baixa produtividade), não são apropriadas ou não apresentam boas condições para o cultivo da soja, ou seja, são áreas de risco para sua produção. Por outro lado, a região formada pelo grupo P1, apresenta boas condições de desenvolvimento agrícola e de produção de soja.

Mediante cada dado analisado, somado à teoria levantada acerca das estruturas agro fundiárias/agroindustriais do Paraná com as contribuições de Martine e Beskow (1987), Moro (1995), Campos (2011) e Paulino (2011), conclui-se que existem diferenças significantes quanto ao perfil agrícola e econômicas dissolvidas em cada grupo de municípios apresentados.

$\mathrm{O}$ universo da soja detém responsabilidades nas transformações de áreas agricultáveis, refletindo em demais formas de uso do solo, concordando, assim, com Bernardes (2008, p.11) quando a autora afirma que: o complexo da soja é posto como aquele responsável pelas transformações mais recentes do sistema capitalista no contexto da globalização do campo, revelando novas formas de articulação espaço/tempo. Tais transformações estão relacionadas, sobretudo ao modelo de acumulação, impulsionado pelo progresso técnico-científico, busca a reprodução ampliada do capital.

É um processo que ao mesmo tempo em que ocorre em uma escala local, acarreta um esquema complexo e denso de transformações sócio espaciais regionais e nacionais (CAMPOS, 2011). Exemplo disso está no Quadro 1, o qual traz a síntese dos resultados de Mann-Kendall. Nele é possível observar a quantidade de municípios que apresentam tendências positivas de aumento da produtividade de soja.

Quanto aos resultados obtidos com este teste estatístico, foi possível observar tendências de aumento da produtividade em 15 municípios, predisposição à diminuição da produtividade em um município e neutralidade na série histórica de 116 municípios e após a espacialização desses resultados, observou-se que há um padrão espacial, ou seja, os municípios que apresentaram resultados estatisticamente significativos de aumento da produtividade da soja localizam-se na porção oeste da área de estudos. Este fato reforça a ideia de que a soja tem sido priorizada nesta parte do Estado.

Estes resultados corroboram com Campos (2011, p.164) quando a autora explicita que as mudanças tecnológicas, juntamente com as demais políticas, criaram transformações sócio espaciais no Paraná. A inserção das inovações tecnológicas na agricultura e a entrada maciça de capital, através dos financiamentos, imprimiram uma nova dinâmica no meio rural no Sul do Brasil (CARGNIN e BEZZI, 2011).

Segundo Farias (2008), as políticas públicas vêm na forma de investimento com a intenção de conduzir trabalhos visando identificar estratégias associadas ao zoneamento climático, melhoramento genético, manejo e irrigação. Conforme este mesmo autor, os avanços tecnológicos em prol do monitoramento e do zoneamento agrícola da soja no decorrer dos últimos dez anos são expressivos e com parcerias com instituições nacionais (e.g. IAPAR, ESALQ) e internacionais (e.g. USDA-ARS, JIRCAS).

Em 2006, por exemplo, Farias et al. (2006) mostraram que já é possível atualizar alguns procedimentos utilizados no campo para melhoria da qualidade dos produtos gerados. Assim, novos avanços, sobretudo, aqueles relacionados à modelagem e a simulações do crescimento de culturas agrícolas vêm sendo testados em condições operacionais inovadores.

\section{Agradecimentos}

O Autor agradece à FAPESP - Fundação de Amparo à Pesquisa do Estado de São Paulo pelo financiamento, concessão da bolsa e da reserva técnica. Processos: 2011/03087-4 e 2014/01071-1.

\section{Referências}

AGEITEC - Agência Embrapa de Informações Tecnológica. Disponível em: http://www.agencia.cnptia.embrapa.br/gestor/ soja/arvore/CONTAG01_10_271020069131.html. Acesso em: 01. Jul. 2017.

BERNARDES, J. A. As estratégias do capital no complexo da soja. In: CASTRO, I. E. GOMES, P. C. C. CORREA, R. L. (Org.) Brasil Questões atuais da reorganização do Território. 4a Edição, Rio de Janeiro: Bertrand Brasil, 2008. 
CAMPOS, M. C. A Embrapa/Soja em Londrina-PR a pesquisa agrícola de um país moderno. 2011. 120p. Tese (Doutorado em Geografia) - Universidade Federal de Santa Catarina, Florianópolis, 2011.

CAMPOS, M. C. Modernização da agricultura, expansão da soja no brasil e as transformações socioespaciais no Paraná. Revista Geografar. Curitiba, v.6, n.1, p.161-191, 2011

CARGNIN, M.; BEZZI, M. L.; CASTILHO, J. A cadeia produtiva da soja como agente reorganizador do seu espaço agrário. Raega - O Espaço Geográfico em Análise, v. 21, abr. 2011.

CARMELLO, V.; SILVESTRE, M. R.; SANT’ANNA NETO, J. L. Desigualdade no campo e o risco climático em áreas de produção da soja no sul do Brasil. In: Lourenço, L (Org.). Multidimensão e territórios de risco. 1 ed. Imprensa da Universidade de Coimbra, 2014. DOI: 10.14195/978-989-96253-3-4_58.

CARMELLO, V. Análise da variabilidade das chuvas e sua relação com a produtividade da soja na vertente paranaense da bacia do rio Paranapanema. 2013. Dissertação (Mestrado em geografia). Faculdade de Ciência e Tecnologia - UNESP. Presidente Prudente.

CARMELLO, V.; SANT’ANNA NETO, J.L. Rainfall Variability and Soybean Yield in Paraná State, Southern Brazil. International Journal of Environmental \& Agriculture Research. Vol-2, Issue-1, January- 2016.

FARIAS, J. R. B. Aprimoramento Tecnológico para Redução de Perdas de Soja por Seca em Sistemas Agrícolas Sustentáveis. Empresa Brasileira de Pesquisas Agropecuárias. 2008

FARIAS, J. R. B.; ASSAD, E. D.; EVANGELISTA, R. S. M.; MARIN, F. R. Avanços tecnológicos para monitoramento do zoneamento agrícola. Empresa Brasileira de Pesquisas Agropecuárias. 2006

MARTINE, G.; BESKOW, P.R. O modelo, os instrumentos e as transformações na estrutura de produção agrícola. In: MARTINE, G. e GARCIA, R. C. (ORG). Os impactos sociais da modernização agrícola. São Paulo, Caetés, 1987, p.19-39

MARTINE, G.; GARCIA, R. C. Os impactos sociais da modernização agrícola. São Paulo: Caetés, 1987.

MOREIRA, R. Pensar e ser em Geografia. São Paulo: Ed. Contexto, 2007.

MORO, D. A. Aspectos geográficos da modernização agrícola no norte do Paraná. Boletim de Geografia. Maringá, Ano 13, n. 13. 1995.

PAULA, A. E.; FAVERET FILHO, P. Panorama do complexo soja. Disponível em: http://www.inagro.org.br/publicacoes/Soja. pdf. Acesso: 16. jul. 2013.

PAULINO, E. T. Estrutura fundiária e dinâmica socioterritorial no campo brasileiro. Revista Mercator. Fortaleza. v. 10, n. $23,2011$.

RAMOS, J. P.; BOAVA, A. P.; DONATO, L. Assentamentos rurais: mapeamento e número de famílias contempladas no noroeste do Paraná - Brasil. Revista Geográfica de América Central. San Jose; 2011. p. 1-12.

REZENDE, L. P. F.; PARRE, J. L. A hierarquização dos municípios paranaenses segundo as suas atividades agrícolas. Revista UNIOESTE. Disponível em: e-revista.unioeste.br/index.php/gepec/article/viewFile/315/231. Acesso em: 20 jul. 2013.

SILVESTRE, M. R; SANT’ANNA NETO, J. L; FLORES, E. F. Critérios estatísticos para definir anos padrão: uma contribuição à climatologia geográfica. Revista Formação, Presidente Prudente, v. 2 n.20, p. 23-53, 2013.

SORJ, B. Estado e classes socias, na agricultura brasileira, Rio de Janeiro, Zahar, 1980.

TAVARES, C. E. C. Fatores críticos à competitividade da soja no Paraná e no Mato Grosso. Disponível em:http://www.conab. gov.br/conabweb/download/cas/especiais/trabalho_sobre_competitividade_soja_mt_e_pr.pdf. Acesso em: 20 jun. 2013

TIAN. Y. XU, Y. P. BOOIJ, M. J, LIN, S.; ZHANG, Q.; LOU, Z. Detection of trends in precipitation extremes in Zhejiang, east China. Theory Appl Climate, v.107, 2012. 
WILKS, D.S. Statistical methods in the atmospheric sciences: an introduction. New York: Academic Press, 1995.

ZHANG, W.; YAN, Y.; ZHENG, J.; LI, L.; DONG, X.; CAI, H. Temporal and spatial variability of annual extreme water level in the Pearl River Delta region, China. Global and Planetary Change, v. 69, 2009.

\section{Vinicius Carmello}

Universidade Estadual Paulista - UNESP, Presidente Prudente, SP, Brasil

Programa de Pós-Graduação em Geografia

Email: viniciuscarmello@gmail.com

Participação do autor:

Único autor, realizou a pesquisa, análise e interpretação de dados e redigiu todo o trabalho. 